\title{
DUPLA LESÃO PONTINA DE FISHER
}

\author{
FERNANDO GULLHON *
}

LEA F, VIEIRA**

En 1967, C. Miller Fisher relatou a observação de uma síndrome ocular caracterizada por paralisia dos movimentos laterais en um olho associada a impossibilidade da adução do olho oposto, a que chamou de "one-and-a-half syndrome", e que a seu ver era causada por lesão pontina 2. Em 1965 e mais detalhadamente em 1978 o mesmo autor descreveu nova sindrome de origem pontina caracterizada por fraqueza e sinais piramidais num hemicorpo associados a ataxia cerebelar no mesmo lado 3 .

Em 1985 tivemos oportunidade de observar em uma paciente vitima de acidente vascular cerebral de localização pontina, a associação, entre outros sinais neurológicos, dessas duas síndromes, configurando um quadro clínico inédito.

\section{OBSERVAÇO}

L.P.A., 45 anos, feminina, morena, natural de MG, registro (HBDF) 1079878. Foi internada em 21-11-85 com história de que havia 15 dias sofrera episódios de mal-estar cefálico, com tontura, vómitos e «dormencia» (perda da força), no hemicorpo direito, porém sem perda da consclència. Ao ser vista por um médico no dia seguinte foi verificada hipertensão arterial. Desde então observa que além da fraqueza no hemicorpo direito tem dificuldade visual e sua boca está desviada para a direita. Sabia ser hipertensa porém năo fazia uso de medicamento. Ao exame físico apresentava-se em bom estado geral com PA de $200 \times 120 \mathrm{mmHg}$. O ritmo cardiaco era regular, em dois tempos, com hiperfonese da segunda bulha. Tórax e abdome sem anormalidades. Do ponto de vista neurológico apresentava-se lúcida, orientada e cooperadora. Não consegula deambular. O exame dos nervos cranlanos revelou: estrabismo divergente à direita; paralisia do olhar conjugado para a esquerda; no olhar conjugado para a direita havia paralisla do reto medial esquerdo $e$ o olho direito ao iabduzir apresentava abalos nistagmóides; movimentos verticais preservados e convergência pouco ampla, esbocada; pupilas normais fotorreagentes (Figs. 1 e 2). Năo foram pesquisados os movimentos oculares à estimulaçăo labiríntica. Paralisia facial periférica à esquerda, com lagoftalmo e sinal de Bell. Paresia do trigêmeo à esquerda com díscreto desvio da mandibula para a esquerda ao abrir a boca. Demais nervos cranianos normais. Hemihipoestesia superficial esquerda poupando a face. Noção de posição segmentar normal. Hemiataxia com dismetria e decomposiçăo dos movimentos nos membros superior e inferior direftos. Năo foram observados de inicio sinais piramidais. No quinto dia de internação observou-se sinal de Babinski à direita. Teve alta no $28^{\circ}$ dia da interna-

* Professor Adjunto, Neurologia, Universidade de Brasilia; Neurologista do Hospital de Base do DF (HBDF); * Medica Residente da Unidade de Neurologia do HBDF. 


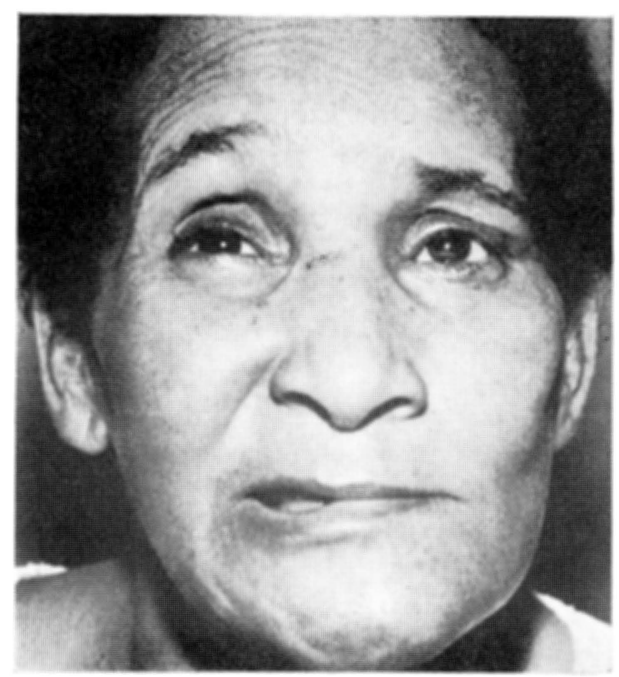

Fig. 1 - Caso L. P. A.. Posigão do olhar em repouso: discreto estrabismo divergente à direitia. Paralisia facial periférica à esquerda.
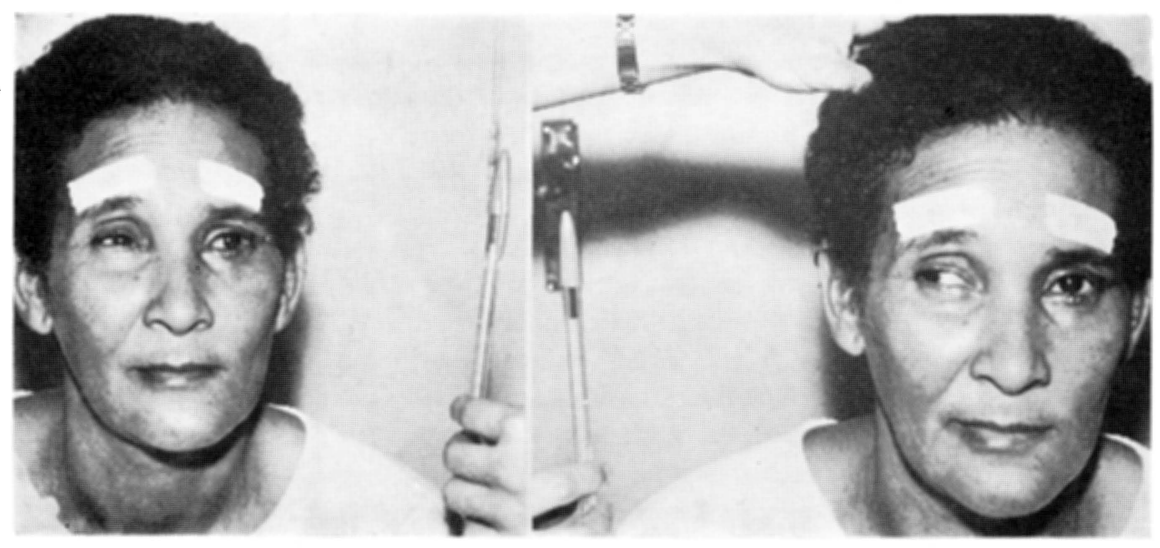

Fig. 2 - Caso L. P. A.. A esquerda, paralisia do olhar conjugado para a esquerdia. A direita, oftalmoplegia internuclear; paresia do reto medial no olhar para a direita.

ção quando já deambulava com apoio, mas ainda apresentava hemiataxia e hemihipoestesia à direita; a movimentaçāo ocular havia melhorado discretamente e o olho esquerdo já ultrapassava levemente a linha média no movimento de adução. A PA mantinha-se em 150x90 sob a ação de medicamentos. Exames complementares — ECG: sobrecarga atrial e ventricular esquerdas. Rx do tórax: aumento do arco ventricular esquerdo $\theta$ 
da croça da aorta. Pulmões normais. Rx do crânio e tomografí computadorizada do crânio: normais. Hemograma completo e exame sumário de urina normais. VDRL não reagente. Glicemia $140 \mathrm{mg} \%$; colesterol $222 \mathrm{mg} \%$; triglicerídeos $135 \mathrm{mg} \%$; ácido úrico $8 \mathrm{mg} \%$.

\section{COMENTÁRIOS}

Os distúrbios do olhar conjugado horizontal não estão, em todos os casos descritos na literatura, perfeitamente bem explicados. Desde a observaçăo original de Foville 4 estudam-se as vias e conexões dos sistemas oculógiros e até hoje persistem algumas dúvidas no seu conhecimento. O núcleo do abducente parece estar constituido de dois tipos de neurônios: neurônios motores que dão origem ao nervo abducente e neurônios internunciais que propiciariam as aferências de vários locais do sistema nervoso aos primeiros, na execução do movimento de abdução do olho. Para que os olhos se desviem horizontalmente para a diretita ou para a esquerda além da estimulaçăo do reto lateral é necessária a ativação do subnúcleo do oculomotor para o reto medial do lado oposto e isto parece ser produzido através da substância reticular paramediana da ponte e em seguida pelo fascículo longitudinal medial (FLM). Tal organização permite admitir, como Fisher o fez, que uma lesão envolvendo simultaneamente a substância reticular pontina e o FLM poderia causar paralisia do olhar conjugado para o lado da lesão associada à impossibilidade da adução do olho desse mesmo lado quando do desvio dos olhos para o lado oposto, o que equivaleria à associação de paralisia do olhar conjugado com oftalmoplegia internuclear. Para que a sindrome fosse completa deveria ser observado nistagmo do olho abduzido no olhar para o lado oposto ao da lesão, e a convergência deveria estar preservada.

Com relação à hemiataxia controlateral à lesão a explicação não é menos difícil. As ataxias por lesão vascular da ponte costumam ser ipsolaterais, seja porque a região laterodorsal é a acometida, envolvendo os pedúnculos cerebelares inferior e/ou médio, seja porque ocorre simultaneamente isquemia do cerebelo. Nas lesões paramedianas, como parece tratar-se a do caso em apreço, a explicação mais adequada parece ser a que o próprio Fisher propôs: acometimento do sistema córtico-ponto-cerebelar. De fato, este sistema, que se origina no córtex cerebral, faz conexōes com os núcleos pontinos situados de maneira mais ou menos esparsa na região paramediana da ponte. A partir dai os neurônios pontinos enviam seus axônios ao cerebelo, após cruzarem a linha média, através do pedúnculo cerebelar médio do lado oposto 1 . Assim, o comprometimento das fibras ponto-cerebelares antes do seu cruzamento justificaria a ataxia do lado oposto, tal como ocorre eventualmente em lesões mais altas, mesencefálicas ou talâmicas. A dificuldade, por tratar-se de lesão pontina, é que este cruzamento do sistema córtico-ponto-cerebelar não é bem conhecido e à primeira vista, como $\mathrm{C}$. Miller Fisher comenta, seria mais razoável esperar-se uma ataxia bilateral já que a lesão é próxima da linha média. Os demais sinais encontrados no caso comprovam a localização pontina da lesão e sua expansão mais lateral do que ventral. O comprometimento do feixe córtico-espinhal foi muito discreto o que faz diferença com os casos descritos por Fisher nos quais os sinais piramidais eram mais evidentes. 
Por se tratar de curiosa associação de duas sindromes estudadas pelo mesmo autor, propomos que o conjunto das sindromes "one-and-a-half" e hemiparesia atáxica, seja denominado de "dupla lesão pontina de Fisher". Infelizmente, a tomografia computadorizada não logrou evidenciar a topografia da lesão.

\section{RESUMO}

C. Miller Fisher descreveu separadamente duas síndromes pontinas, que denominou de "one-and-a-half syndrome" e de "hemiparesia atáxica". Os autores descrevem o caso de uma paciente que por ocasiăo de acidente vascular cerebral de localizaçăo pontina desenvolveu simultaneamente estas duas síndromes.

\section{SUMMARY}

\section{Double pontine lesion of Fisher.}

C. Miller Fisher described separately two pontine syndromes, that he called "the one-and-a-half syndrome" and "ataxic hemiparesis". The authors report the case of a woman who developed simultaneously the two syndromes, caused by a stroke of pontine localization, and comment about the structures involved by the lesion.

\section{REFERENCIAS}

1. CARPENTER, M.B. - Neuroanatomia Humana, Ed. 7. Ed. Interamericana, Rio de Janeiro, 1978.

2. FISHER, C.M. - Some neuro-ophtalmological observations. J. Neurol, Neurosurg. Psychiat. 30:383, 1967.

3. FISHER, C.M. — Ataxic hemiparesis. Arch. Neurol. 35:126, 1978.

4. Foville, A.L. - Bulletin de la Societé Anatomique de Paris 33:373, 1858.

Universidaaie de Brasilia, Campus Universitário - Asa Norte 70910 - Brasília, DF Brasil. 